\title{
NACO and the World Bank are correct in their 总 crackdowns
}

\section{To the editor:}

We welcome your piece "India continues crackdown, dismissing hundreds of AIDS groups" in the February 2008 issue of Nature Medicine ${ }^{1}$. We, along with two other investigators from Claflin University, traveled to various parts of India from June 2006 to July 2007 to explore the major sources of HIV transmission and find ways to implement culturally sensitive educational and prevention plans. From our experience on site and from subsequent research, we have been surprised and disturbed to learn of the inadequate oversight of nongovernmental organizations (NGOs) by India's National AIDS Control Organisation (NACO).

Our team is not the first to deplore the creation of phony NGOs, whose main purpose is not to serve people with HIV/AIDS or to slow the tide of an epidemic, but rather to serve their own avarice. Moreover, the rise of the MONGO (My Own NonGovernmental Organization) is not unique to India; it also plagues other areas where
NGOs are entrusted with responsibility and resources. Unfortunately, MONGOs taint the reputation of the NGOs that are legitimate.

It is abundantly clear that NACO must have the will, and the political backing, to support the legitimate NGOs while weeding out the corrupt ones. The efforts of both NACO and the World Bank to squelch the corruption in HIV/AIDS spending are justified, but the two organizations must take care not to demolish domestic and international trust in NGOs.

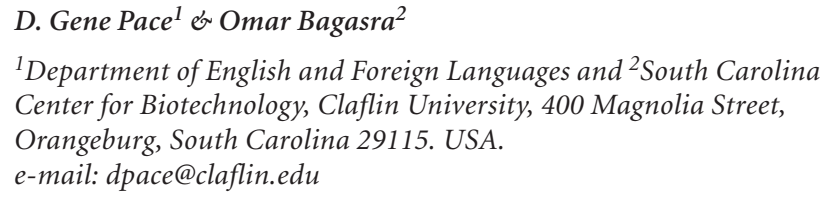

1. Padma, T.V. Nat. Med. 14, 227 (2008). 